\title{
Of Making Many Books
}

There is No End ... and Much Cataloguing Wearies the Body:

RDA in ANZTLA Libraries Workshop

by Jenny Clarke

This is the "speaker's" version of the ANZTLA Conference RDA workshop presentation. The slides used are not available for publishing in the journal but I'm happy to pass on the Cheat Sheet distributed at the conference to ANZTLA members and also answer any questions as they arise

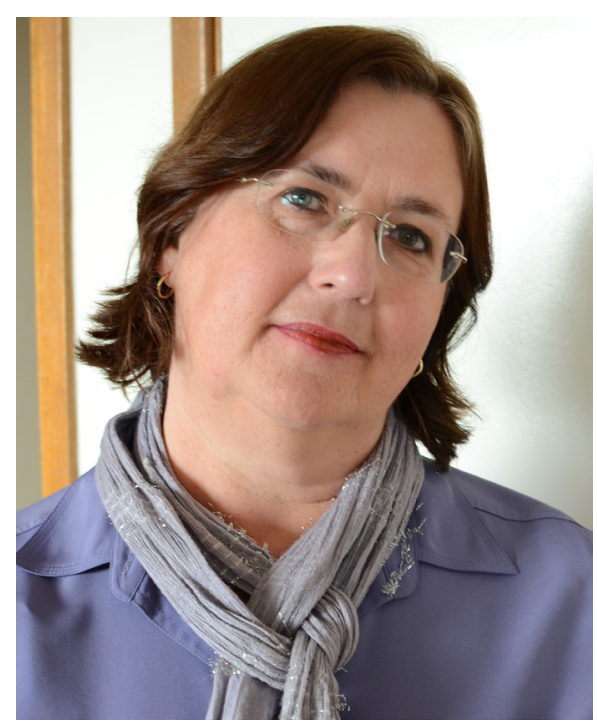
for any ANZTLA libraries implementing $R D A$. his workshop is intended mostly for those who are cataloguing at the moment. It assumes you are using a MARC based system and are basically familiar with AACR2. For the next hour or so, I will go through the main changes between Resource Description and Access (RDA) and Anglo American Cataloguing Rules $2^{\text {nd }}$ ed (AACR2r) and try to cover the ordinary things a cataloguer needs to know. (The Cheat Sheet, which should be on your chair, is a 4 page distillation of what I'll cover). After tea we will work in groups on some standard MARC records marking up the changes needed to convert an existing record from one set of rules to the other. 


\section{"RDA only affects}

the rules for what

goes into a catalogue

record (or the

metadata for a

webpage). It uses

some new MARC

tags but it doesn't

replace MARC21.

For some of you, if

your current system

cannot accept or

work with the new

tags, you really can't

fully adopt the new

standard. The world

will not end if you

choose to stay with

AACR2."

\section{What is RDA?}

Firstly, for those of you who are coming to this cold, RDA is the new set of cataloguing rules that finally! became the international descriptive standard on April 1 this year. From that date, all new cataloguing from the major libraries like Library of Congress, National Library of Australia, National Library of New Zealand, the British Library, National Library of Canada uses RDA. Libraries Australia and OCLC now prefer RDA records over AACR2 ones.

$\mathrm{RDA}$ only affects the rules for what goes into a catalogue record (or the metadata for a webpage). It uses some new MARC tags but it doesn't replace MARC21. For some of you, if your current system cannot accept or work with the new tags, you really can't fully adopt the new standard. The world will not end if you choose to stay with AACR2. You can still download records from the major agencies; you will just need to change some of the tagging once you load them. You can still contribute your records back to union catalogues like Libraries Australia and TePuna.

Eventually it will become more expensive for you to remain on the old standard and you should ensure any new library system you adopt can handle RDA, but my guess is that time is a few years away. I recommend you adopt the new rules affecting access points / authorised headings now. "Hybrid" records (AACR2 records with some RDA features) and "Hybrid" catalogues (some full RDA, some hybrid, some AACR2 records) will really be the norm for most of the library world for the foreseeable future.

The rules for RDA are in an online subscription product known as the $R D A$ Toolkit http://rdatoolkit.org/. There is a loose-leaf print version but the online version is superior.

This website links to authoritative examples of $\mathrm{RDA}$ in use: http://www.loc.gov/catworkshop/RDA\%20training\%20materials/ SCT\%20RDA\%20Records\%20TG/index.html

\section{What is different?}

\section{Underlying theory and terms}

Get ready for lots of jargon, just let it wash over you, eventually it will become familiar.

RDA is based on a theoretical framework known as Functional Requirements for Bibliographic Records (FRBR - pronounced Ferber) and Functional Requirements for Authority Data (FRAD).

The core of FRBR is 3 types of Entities

Group 1 Entities - product of intellectual or artistic endeavour

- Work - a distinct intellectual or artistic creation This is the idea in abstract

- Expression - the realization of a work This is what the idea became in substance - A book? A painting? A speech? A translation or adaptation of someone else's work? 


\section{"There are no}

prescribed sources, there are preferred sources (such as title page) and any part of the resource can be used if the preferred source does not contain the information needed. In general, if the information is anywhere on the item it is OK to use."
- Manifestation-physicalembodimentofanexpressionofawork This is the publishing run for book where there are lots of them the same - most of our cataloguing work is at this level and in most cases the one MARC record will be describing bits of all the above levels

- Item - example of a manifestation This is your copy, with its stamps and barcode and shelf number

Group 2 Entities - those responsible for Group 1 things -

- Person - e.g. a personal author or editor or illustrator

- Family - e.g. a family archive

- Corporate body - e.g. the issuer of an annual report, a conference committee, a publisher

Group 3 Entities - subjects of Group 1 things -

- Concept

- Object

- Event

You can safely ignore group 3, the RDA section is not even written and Library of Congress Subject Headings remain the norm.

You only need to pay attention to subject headings that are really a Group 1 or a Group 2 entity. The new rules cover the subject headings for a book of the bible (Group 1 work, 630) or a biography of a saint (Group 2 person, 600) but have no impact on a concept like Grace or Theology (650).

$\mathrm{RDA}$ introduces other terms too. In AACR2 there are 3 levels of description (level 2 is the normal minimum level for a finished record) but RDA is more interested in Core and Non core elements than the record as a whole. In RDA a minimum level record contains all the relevant Core elements. More than this is optional and expected if it helps your user. The most helpful list of what is the accepted Core Standard for Australian libraries can be found at: http://www.nla. gov.au/librariesaustralia/services/cataloguing/standards/requireddata-elements/

Headings and terms like Author main entry or added title entry are now access points. The authorised form of someone's name is the preferred name. Uniform title is now preferred title. There are no prescribed sources, there are preferred sources (such as title page) and any part of the resource can be used if the preferred source does not contain the information needed. In general, if the information is anywhere on the item it is OK to use. Square brackets are only used now for information you sourced outside any part of the item itself (e.g. from the web, publisher's catalogue, your knowledge, best guess etc).

RDA places strong emphasis on spelling out relationships. AACR2 records the fact that a relationship exists, such as this is the author, this is the editor, but RDA encourages the use of relationship designators (\$e after a heading). 
"Very few abbreviations

are used in

RDA. You

only use

abbreviations

if that is how

the data is

presented on

the source."
Transcribe more, abbreviate less

It is now the norm to transcribe everything from the 245 (title) to the end of the 490 (series) exactly as it appears on the item.

When RDA was first released in 2010 it looked as though it required you to copy the title information in capitals if that was how it appeared. This is no longer required - though you can choose to do this if you want.

For statements of responsibility $(245 \$ c)$ transcribe as it appears, e.g. foreword by the late Dr Leon Goldman. by the Reverend R.M. Dickey

Treat a noun phrase associated with a statement of responsibility as part of it, e.g. $24510 \$$ a People of the Bible / \$c dramatised adaptations by Barry Campbell (in AACR2 was \$b dramatised adaptations / \$c by Barry Campbell)

Very few abbreviations are used in RDA. You only use abbreviations if that is how the data is presented on the source.

If the Source reads: Second edition

AACR2: 2nd ed.

RDA: Second edition

If the Source reads Second ed.

AACR2: 2nd ed.

RDA: $\quad$ Second ed.

Abbreviations are no longer used in Publication details and you enter the Publisher's name as it appears on the source.

If the Source reads: Department of Theology, University of Victoria, Victoria, British Columbia, Canada

AACR2: \$a Victoria, B.C. : \$b Dept. of Theology, University of Victoria, \$c 1979

RDA: \$a Victoria, British Columbia, Canada : \$b Department of Theology, University of Victoria, \$c 1979

In the above example note that Dept. is now spelled out and British Columbia and Canada are both included because that is how they appear on the source.

If the Source reads: Department of Theology, ACU, Strathfield

AACR2: \$a Strathfield, N.S.W. : \$b Dept. of Theology, Australian Catholic University, \$c 1999

RDA: \$a Strathfield : \$b Department of Theology, ACU, \$c 1999

In this example, NSW does not appear on the source so it is not included in the publication details and it could only be abbreviated if that was how it appeared. (The rules are different for Access points / Headings. This just applies to the transcribed/descriptive parts of a record).

A recent rule change means you can include a larger jurisdiction if it is needed for identification or to help your users. If your system does not include 008 codes which cover this, you may want to adopt this option. (Most libraries are not).

So if the source reads Perth and your users may think the resource is Scottish:

AACR2: \$a Perth, W.A.

RDA: \$a Perth

RDA (opt): \$a Perth [Western Australia] 
"If a title alone is

very unhelpful, no

longer supply extra

information like

[proceedings] or

[program] in the

title. If you have the

ANZTLA Conference

proceedings, the

ANZTLA Conference

poster and the

ANZTLA Conference

programme and

each of them have

just ANZTLA

Conference as the

title, this is how the

title will appear in

each record."
The AACR2 Latin abbreviations have been dropped.

For unknown place of publication,

AACR2: $\quad$ \$a [S.1.]

RDA: $\quad$ \$a [Place of publication not identified]

For unknown publisher,

AACR2: \$b [s.n.]

RDA: \$b [publisher not identified]

For unknown dates, [n.d.] in AACR2, you can use [no date] but RDA strongly encourages you to supply whatever date information you can. Your guess will help someone looking at it a century from now. For example, use

between [date] and [date]

not before [date]

not after [date]

[date?]

$2641 \$$ a [Place of publication not identified] : \$b [publisher not identified], \$c [2012?]

Mistakes

Transcribe inaccuracies as they appear.

If the source reads: Escatology for theologians

AACR2: 24510 \$a Escatology [sic] for theologians

RDA: $\quad 24510$ \$a Escatology for theologians

246 1_\$i Title should read: \$a Eschatology for theologians

(or use a note if your system cannot use $\$ \mathrm{i}$ )

If a title alone is very unhelpful, no longer supply extra information like [proceedings] or [program] in the title. If you have the ANZTLA Conference proceedings, the ANZTLA Conference poster and the ANZTLA Conference programme and each of them have just ANZTLA Conference as the title, this is how the title will appear in each record.

No more rule of three

Another sensible change is that the Rule of three is gone. You now list all the authors in the statement of responsibility. The first named now gets a main entry and the others are normally traced.

AACR2 : 24500 \$a Four views on free will / \$c John Martin Fischer. [et al.]

700 1_ \$a Fischer, John Martin, \$d 1952-

RDA : 1001 1_ \$a Fischer, John Martin, \$d 1952- , \$e author

24510 \$a Four views on free will / \$c John Martin Fischer, Robert Kane, Derk Pereboom, Manuel Vargas

7001 1_ \$a Kane, Robert L., \$d 1938- ,\$e author

7001 1_ \$a Pereboom, Derk, \$d 1957-, \$e author

700 1_ \$a Vargas, Manuel, \$e author

Optionally, you can list only the first name and summarise the omission

1001 1_ \$a Fischer, John Martin, \$d 1952- , \$e author 
"264 replaces the old 260 and will

be the main area

those staying with

AACR2 will be forced

to amend when

importing $R D A$

records."
24510 \$a Four views on free will / \$c John Martin Fischer [and three others]

this record could still have a 100 and three 700 fields as different rules govern the $\$ c$ and the access points

editors are still only entered in the 700 field, but all of them are able to be entered

MARC changes / new fields for Publication details

I'll move on now to some of the new MARC tags. 264 replaces the old 260 and will be the main area those staying with AACR2 will be forced to amend when importing RDA records. It was only adopted by the national agencies at the beginning of 2013, until then it was only going to be an option.

The new field separates out Production, Publication, Distribution, Manufacture, and Copyright Notice - the fields are repeatable and the second indicator flags what the field contains:

0 - Production

1 - Publication

2 - Distribution

3 - Manufacture

4 - Copyright notice date

Only 2641 for Publication is core. This means you need to include/ code it even though it is not always sensible.

For example, you only have distribution information for a DVD. You need to code 2641 AND 2642 :

$2641 \$$ a [Place of publication not identified] :\$b [publisher not identified], \$c [2005?]

2642 \$a Avalon : \$b Maxwell distribution, \$c 2012

Another common change you will notice is the copyright date is now included in its own 2644 field. This will only ever contain a \$c

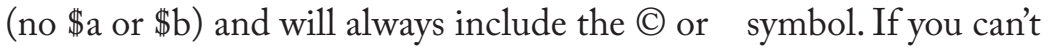
enter the symbol, you must spell out copyright or phonogram before the date. (In AACR2 your could just put $\mathrm{c}$ in front of the date).

Copyright date is only core if there is no stated date of publication or distribution. However, if copyright date is given on the item, it is good practice to include it. Always include it if it differs from the publication date.

Publication Details - Examples

264 _ $\$$ a place : $\$$ b publisher, $\$ \mathrm{c}$ date.

$264 \_1$ \$a New York: \$b Ballantine Books, \$c 1963

264 _4 \$c (1958.

No date of publication, only copyright date given:

$264 \_1$ \$a Sydney : \$b Publisher, \$c[2013]

$264 \_4$ \$c (2013.

Physical description

The main changes you will see for Physical description (300 field) are from the changes to abbreviation practice. From now on p. becomes pages, v. becomes volumes. col. ill. are now colour illustrations. Use "approximately" (not "ca.") and "that is" (not "i.e."). 


\section{"The GMD was}

inconsistent. Some

described the

content (e.g. music),

others described

the carrier (e.g.

filmstrip), and

others were about

the media required

to view/access (e.g.

microform)."
If your item is a text, use "unnumbered" rather than square brackets enclosing the numeral.

However, still use hr. and min. and sec. and $\mathrm{cm}$ and $\mathrm{mm}$. For DVDs and CDs give the dimensions as $12 \mathrm{~cm}$ not $43 / 4 \mathrm{in}$.

MARC Changes / new fields for Content Media Carrier

The GMD has gone and been replaced with Content, media \& carrier types - in 3 new MARC fields.

The GMD was inconsistent. Some described the content (e.g. music), others described the carrier (e.g. filmstrip), and others were about the media required to view/access (e.g. microform).

RDA caters for all of this information in the new $3 \mathrm{xx}$ fields (and uses the existing coded data in 007 and 008). The preferred convention seems to be to code as many as are required in repeated tags.

Content type MARC field 336

"the form of communication through which the content of the resource is expressed and with which human sense it can be perceived"

RDA rule 6.9

Core element (i.e. it is required)

Code a 336 field for as many of these terms are needed to describe the content of your resource. You can only choose a term from the list.

Content type list

cartographic dataset

cartographic image

cartographic moving image

cartographic tactile image

cartographic tactile three-dimensional form

cartographic three-dimensional form

computer dataset

computer program

notated movement

notated music

performed music

sounds

spoken word

still image

tactile image

tactile notated movement

tactile notated music

tactile text

tactile three-dimensional form

text

three-dimensional form

three-dimensional moving image

two-dimensional moving image

If none of the terms listed above apply to the content of the resource being described, record other 


\section{"Carrier type \\ MARC 338}

Describes the

physical apparatus

that contains

the content of

the resource, the

packaging"
Media type MARC field 337

"the general type of device required to view, play, run, etc., the content of a resource"

RDA rule 3.2

RDA - non core

(NLA - mandatory; LA required data elements -337 not required but 007/008 mandatory; UNILINC - required. If you are coding 336 and 338 you might as well do 337)

Code a 337 field for as many of these terms as are needed to describe the medium of your resource. You can only choose a term from the list.

Media type list
audio
computer
microform
microscopic
projected
stereographic
unmediated
video

Carrier type MARC 338

Describes the physical apparatus that contains the content of the resource, the packaging

RDA rule 3.3

Core element (i.e. it is required)

Carrier type list

Audio carriers

audio cartridge

audio cylinder

audio disc

audio roll

audiocassette

audiotape reel

sound-track reel

Computer carriers

computer card

computer chip cartridge

computer disc

computer disc cartridge

computer tape cartridge

computer tape cassette

computer tape reel

online resource

Microform carriers

aperture card

microfiche

microfiche cassette 
“Code a 338 field

for as many of

these terms as are

needed to describe

the carrier of your

resource. You can

only choose a term

from the list." microfilm cartridge

microfilm cassette

microfilm reel

microfilm roll

microfilm slip

microopaque

Microscopic carriers

microscope slide

Projected image carriers

film cartridge

film cassette

film reel

film roll

filmslip

filmstrip

filmstrip cartridge

overhead transparency

slide

Stereographic carriers

stereograph card

stereograph disc

Unmediated carriers

card

flipchart

object

roll

sheet

volume

Video carriers

video cartridge

videocassette

videodisc

videotape reel

Code a 338 field for as many of these terms as are needed to describe the carrier of your resource. You can only choose a term from the list. If none fit, use other [carrier] - for example for a flash drive use other computer carrier.

This is what they look like in a MARC record

( $\$ 2$ is needed because there are other possible lists of terms - BUT libraries only use the RDA ones):

1. Book containing text and pictures

336 \$a text $\$ 2$ rdacontent

336 \$a still image $\$ 2$ rdacontent

337 \$a unmediated $\$ 2$ rdamedia

338 \$a volume $\$ 2$ rdacarrier 


\section{"The preferred}

name is the basis of

the authorised access

point. The name can

be the person's real

name, pseudonym,

title of nobility,

nickname, initials or

other appellation."

\section{DVD}

336 \$a two-dimensional moving image $\$ 2$ rdacontent

$337 \$$ a video $\$ 2$ rdamedia

338 \$a video disc $\$ 2$ rdacarrier

3. Online PDF

$336 \$$ a text $\$ 2$ rdacontent

337 \$a computer $\$ 2$ rdamedia

338 \$a online resource $\$ 2$ rdacarrier

4. Website with maps, text and photographs

336 \$a text $\$ 2$ rdacontent

336 \$a still image $\$ 2$ rdacontent

336 \$a cartographic image \$2 rdacontent

$337 \$$ a computer $\$ 2$ rdamedia

338 \$a online resource $\$ 2$ rdacarrier

ISBN

Officially the ISBN should be coded with hyphens. However, MARC can't handle this so do not use hyphens or spaces in ISBNs. (An ISSN should always have a single hyphen).

That's really all that is needed for describing a resource in $R D A$. I'm going to touch briefly now on Access points so that you have the basic rules for constructing an access point (heading) for a person or corporate body when you can't find an existing authority.

Authorised Access Point for Person

The preferred name is the basis of the authorised access point. The name can be the person's real name, pseudonym, title of nobility, nickname, initials or other appellation.

There are five possible additions to the preferred name, to be used in the order listed. Apart from Titles, the preferred addition is a birth/death date

Additions to preferred name

Title or other designation associated with the person (required)

Title of royalty or nobility - e.g., Anne, Queen of Great Britain

(At ANZTLA Conference early July, "Sir" was excluded from the list of titles, the rule has now changed and it is once more included)

Saint - e.g. 100 \$a Teresa of Avila, \$c Saint

Jr, IV etc - e.g. 100 \$a Davis, Sammy, \$c Jr., \$d 1925-1990

Title of religious rank - e.g. 100 \$a Pius $\$$ b XII, \$c Pope

The term Spirit - e.g. 100 \$a Garland, Judy \$c (Spirit) (there is an author claiming to channel Judy Garland as she writes)

Profession or occupation - e.g. 100 \$a Stone Mountain \$c (Writer)

Date of birth and/or death date is no longer required unless needed to distinguish. It is an optional addition

Use the terms "born", "died", not b., d.

Smith, John, \$d 1978-

Smith, John, \$d 1718-1791

Smith, John, \$d born 1787

Smith, John, \$d died 1773 
"Terms of address

such as Dr, Mrs,

$\mathrm{Mr}$ are also now an

integral part of the

preferred name, but

only where they are

part of a phrase that

consists only of a

forename or surname."
Fuller form of name Add fuller form of name only if it is needed to distinguish. It is an optional addition

Period of activity of person. Add period of activity only if it is needed to distinguish and there are no dates or fuller form. Use the terms "flourished" or "active"

Smith, John, flourished 1705

Smith, John, active 1719-1758

$\mathrm{Xu}$, Zhen, active 1377

Allen, Charles, 17 th century

Profession or occupation Only use this if none of the previous options are available to distinguish. Examples are Writer, Poet, Rapper, Nurse

Smith, John \$c (Nurse)

If a person has multiple identities, establish a preferred name for each of them:

100 \$a Baron Cohen, Sacha, \$d1971-

100 \$a G., Ali

$100 \$$ a Sagdiyev, Borat

Name Entries - other notes

Terms of address such as Dr, Mrs, Mr are also now an integral part of the preferred name, but only where they are part of a phrase that consists only of a forename or surname.

100 \$a Beeton, Mrs.

100 \$a Seuss, Dr.

Names consisting of a phrase are entered as is:

Miss Piggy

Little Richard

Buckskin Bill

Kermit, the Frog

Authorised Access Point for Family

Family has been around for a while in MARC but is new in RDA. It can now be an author or creator, not just a subject. Definition: "two or more persons related by birth, marriage, adoption, civil union, or similar legal status, or who otherwise present themselves as a family".

Authorised Access Point Corporate Body

The good news is it is mostly the same as AACR2. A few things to note:

Do not abbreviate "Department"

Use the native language (or transliterate) - do not use English equivalent

Include frequency in a conference name if the conference does eg Annual Theology Conference

Variant spellings: choose the form found in the first resource received (after you've already checked for an authority!!)

You can add qualifiers if needed to distinguish from something similar 


\section{" $R D A$ introduces}

the concept of

relationship

designators, with

an extensive list in

Appendix I. This is

not a closed list so

you may use other

terms if the ones

listed do not suit

your users."
Examples:

110 2\# \$a Gingerbread (Organisation)

110 2\# \$a Apollo 11 (Spacecraft)

110 2\# \$a World Cup (Cricket)

110 2\# \$a World Cup (Soccer)

111 2\# \$a VALA National Conference on Library Automation \$n(16th :\$d 2012 : \$c Melbourne, Vic.)

111 2\# \$a Burke and Wills Expedition \$d (1860-1861)

110 1\# \$a Queensland. \$b Department of Natural Resources, Mines and Energy

Relationship designators for Persons, Families \& Corporate Bodies

RDA introduces the concept of relationship designators, with an extensive list in Appendix I. This is not a closed list so you may use other terms if the ones listed do not suit your users. Apart from the lists in the Toolkit, another useful source of terms is MARC Code List for Relators at http://www.loc.gov/marc/relators/relaterm.html Examples:

1001 \$a Winton, Tim, \$e author.

7001 \$a Stead, Erin E., \$e illustrator.

7001 \$a Eastwood, Clint, \$d 1930- ,\$e film producer, \$e film director, $\$$ e actor, $\$$ e composer (expression).

7102 \$a British Broadcasting Company, \$e production company

How to identify fully coded RDA records (as opposed to hybrid ones changed by program to have RDA features)?

The 2 accepted conventions are:

AACR2 is indicated by LDR position 18 "a"

RDA use LDR position $18 \mathrm{i}$ to reflect ISBD content

040 \$e rda

This coding should only be applied if the entire record has been examined and upgraded

The Bible (and Koran) changes.

Stemming from removal of English bias, the Koran is now Qu'ran whenever it is used as a title heading

(240, 630, 730, 740, etc).

Stemming from the general removal of abbreviations, N. T. and $\mathrm{O}$. T. are no longer used in Bible headings. The entry now omits O.T./N.T. if it is an intermediate division, and spells it in full if it is the primary division.

$(240,630,730,740)$
AACR2

Bible. \$p O.T.

Bible. \$p N.T.

Bible. \$p O.T. \$p Ezra

Bible. \$p N.T. \$p Gospels
$R D A$

Bible. \$p Old Testament

Bible. \$p New Testament

Bible. \$p Ezra

Bible. \$p Gospels
As I said at the start, the world will not end if you choose to stay with AACR2. Eventually that will be a more expensive decision 
"If you can adopt

full $R D A$, you should

because it makes

your data more

valuable both in and

outside your library."

but at the moment it is a viable choice if you are constrained by your LMS (make sure your next system is compliant).

In the ANZTLA context, it makes sense as a minimum to update existing Bible headings to conform to the new practice. It is a change (like Dept to Department) that most of the bibliographical utilities have already made and so incoming records will probably have this form - and it should be easier for your users. For your original cataloguing, try as far as possible to transcribe what you see on the item and minimise your use of abbreviations. List and trace all the authors. If you can adopt full RDA, you should because it makes your data more valuable both in and outside your library. 